The bond lengths in $\mathrm{ClO}_{4}^{-}$range from 1.387 to 1.428 $\AA$, with a mean of $1.409 \AA$ and the angles in this group are between 104.4 and $113.7^{\circ}$, with a mean of $109.4^{\circ}$. The thermal parameters of the $\mathrm{O}$ atoms are high, but there are no indications of disorder.

A projection of the cation with the thermal ellipsoids at $50 \%$ probability is presented in Fig. 4 .

Apart from van der Waals contacts, there are no other intermolecular interactions.

\section{References}

Baranowski, P., Skolik, J. \& Wiewiórowski, M. (1964). Tetrahedron, 20, 2383-2397.

Birnbaum, G. (1967). Acta Cryst. 23, 526-535.

Boczoń, W., Pieczonka, G. \& Wiewiórowski, M. (1977). Tetrahedron, 33, 2565-2570.

JoHnson, C. K. (1965). ORTEP. Report ORNL-3794. Oak Ridge National Laboratory, Tennessee.
Kaluski, Z., Gusiev, A. J., Struchkov, Yu. T., Skolik, J., BARANOWSKI, P. \& WiEWIÓROWSKI, M. (1972). Bull. Acad. Pol. Sci. Sér. Sci. Chim. 20(1), 1-14.

MaluszyńsKa, H. \& OKaya, Y. (1977a). Acta Cryst. B33, 3049-3054.

Maluszyłska, H. \& Okaya, Y. (1977b). Acta Cryst. B33, 3889-3891.

PrZybylska, M. (1974). Acta Cryst. B30, 2455-2459.

Skolik, J., LANGOWSKA, K. \& WIEWIÓROWSKI, M. (1972). Bull. Acad. Pol. Sci. Sér. Sci. Chim. 20, 383-390.

Skolik, J., Łangowska, K. \& WiewióRowski, M. (1975). Bull. Acad. Pol. Sci. Sér. Sci. Chim. 23, 215-222.

Srivastava, S. N. \& Przybylska, M. (1969). Acta Cryst. B25, 1651-1658.

Syntex (1976). XTL/E-XTL Structure Determination System. Syntex Analytical Instruments, Inc., 10040 Bubb Road, Cupertino, California 95014.

Wiewiórowski, M. \& Baranowski, P. (1967). Bull. Acad. Pol. Sci. Sér. Sci. Chim. 10, 537-542.

Acta Cryst. (1978). B34, 3134-3137

\title{
The Structures of Anhydrous 1,5- and 2,6-Diazanaphthalene
}

\author{
By D. M. W. van den Ham, G. J. van Hummel and C. Huiszoon \\ Chemical Physics Laboratory, Twente University of Technology, PO Box 217, Enschede, The Netherlands
}

(Received 18 November 1977; accepted 5 June 1978)

\begin{abstract}
Both molecules have the formula $\mathrm{C}_{8} \mathrm{H}_{6} \mathrm{~N}_{2} .1,5-$ Diazanaphthalene: tetragonal, $P 4_{1,3} 22_{1}\left(P 4_{1} 2_{1} 2\right.$ was chosen), $a=b=7.4079$ (3), $c=24.089$ (2) A, $Z=8$, $V=1321.9$ (1) $\AA^{3}, D_{x}=1.308 \mathrm{~g} \mathrm{~cm}^{-3}$, weighted $R=$ $0.041, \mu($ Mo $K \alpha)=0.76 \mathrm{~cm}^{-1}$. 2,6-Diazanaphthalene: monoclinic, $P 2_{1} / c, a=4.8281$ (4), $b=5.5254$ (3), $c=$ 12.0834 (8) $\AA, \beta=94.28$ (2) $, Z=2, V=321.46$ (4) $\AA^{3}, D_{x}=1.345 \mathrm{~g} \mathrm{~cm}^{-3}$, weighted $R=0.042, \mu($ Mo $K a)$ $=0.78 \mathrm{~cm}^{-1}$. Data collection for both cases was carried out at $20^{\circ} \mathrm{C}$. The $\mathrm{X}$-ray proton geometries differ from those previously proposed [Lee \& Gilson (1976). Can. J. Chem. 54, 2783-2787] on the basis of NMR experiments.
\end{abstract}

Introduction. In our laboratory, the chemical and physical properties of diazanaphthalenes are studied [e.g. Huiszoon, van Hummel \& van den Ham (1977)].

In this paper we report the X-ray analysis of those isomers that can be expected to be centrosymmetric: 1,5- and 2,6-diazanaphthalene. The dihydrates of these compounds have been investigated earlier by Brufani, Fedeli, Giacomello, Riccieri \& Vaciago (1966). Our interest in the crystal structures of the anhydrous compounds originates from our objective to compare experimental heats of sublimation of all diaza- naphthalenes with heats of sublimation calculated on the basis of intermolecular force fields.

Recently, Lee \& Gilson (1976) reported an NMR study on the title compounds. From the NMR data and with the aid of the X-ray data of Brufani et al. (1966), these authors proposed proton geometries. These geometries differ from those derived by the present $\mathrm{X}$ ray experiment.

1,5- and 2,6-diazanaphthalene were prepared following the instructions of Albert (1960) and Danieli \& Ricci (1973) respectively. Both compounds were purified by passing them through a column packed with basic alumina. After thorough drying over molecular sieves, the solvent was evaporated and the residual compounds were sublimed in vacuo. The crystals were sealed in Lindemann-glass capillaries. Special dry

\section{Table 1. Details of data collection}

$\begin{array}{ccccc}\text { Compound } & \theta \text {-range }\left(^{\circ}\right) & \begin{array}{c}\text { Scan } \\ \text { width }\left({ }^{\circ}\right)\end{array} & \begin{array}{c}\text { Scan } \\ \text { time }(\mathrm{s})\end{array} & \begin{array}{c}\text { Number of } \\ \text { reflexions } \\ \text { measured }\end{array} \\ \text { 1.5-Diazanaphthalene } & 3 \cdot 0-25 \cdot 0 & 1.50 & 50 & 2792(k, l \leq 0) \\ \text { 2.6-Diazanaphthalene } & 2 \cdot 5-35 \cdot 0 & 1.60 & 40 & 3142(l \geq 0)\end{array}$

Detector aperture in both cases: horizontal: $2^{\circ}$, vertical: $1^{\circ}$. 
conditions were necessary for the mounting of the 1,5diazanaphthalene crystal. The maximum linear dimensions of the crystals were about $0.7 \mathrm{~mm}$. Both data sets have been obtained using the $\omega-2 \theta$ scan mode.

Cell constants and intensity data were obtained at $20^{\circ} \mathrm{C}$ with a computer-controlled single-crystal diffractometer (Philips PW 1100) using graphite-monochromated Mo $K \alpha$ radiation, $\lambda=0.7107 \AA$. Details of the data collection have been listed in Table 1 .

For 1,5-diazanaphthalene sets of symmetry-related reflexions, $h k l, \bar{h} k l, k h l$ and $\bar{k} h l$, were measured. From these measurements the intensities for the reflexions $h k l$ with $h, k, l$ non-negative and $h \geq k$ were calculated. For the 776 independent reflexions in the data set, 699 intensities were obtained as the weighted mean of equivalent reflexions. In 77 cases the spread in the intensities in a set of equivalent reflexions was such that the largest intensity of the set was assumed to represent the most probable value.

The same procedure was applied for 2,6diazanaphthalene where the intensities of the reflexions $h k l$, with $k$ and $l$ non-negative, were obtained from the symmetry-related reflexions $h k l$ and $h \bar{k} l .1336$ intensities were obtained as the weighted mean of equivalent reflexions; in 235 cases the largest intensity was chosen. The indices of internal consistency are 3.3 and $2.8 \%$ for 1,5- and 2,6-diazanaphthalene respectively. These figures have been calculated on the basis of all measured reflexions (Table 1). [The index of internal consistency, $R_{l}$, is defined as follows: $R_{l}=\sum_{i}\left(\sum_{j} \mid I_{i, j}\right.$ - $\left.\bar{I}_{i} \mid\right) / \sum_{i}\left(\sum_{j} I_{i, j}\right)$, where $\sum_{j}$ represents the summation over the symmetry-related reflexions of set $i, \sum_{i}$ represents the summation over all sets of symmetryrelated reflexions, $I_{i, j}$ is the intensity of reflexion $j$ of set $i, \bar{I}_{i}$ is the weighted average of the reflexions of set $i$.]
The variances, $S^{2}(I)$, of the intensity data were calculated with a method proposed by McCandlish, Stout \& Andrews (1975). The values of the parameters $K, S^{2}(K)$ and $\bar{P}$, occurring in the formulae of McCandlish et al. (1975), were for 1,5-diazanaphthalene: $K=1.08, S^{2}(K)=1.8 \times 10^{-4}, \bar{P}=0.004$ and for 2,6-diazanaphthalene: $K=1 \cdot 00, S^{2}(K)=1 \cdot 2$ $\times 10^{-4}, \bar{P}=0.005$.

The structures were solved with the aid of the multisolution program MULTAN of Germain, Main \& Woolfson (1971). The $E$ maps showed the positions of all non-H atoms. The refinements were carried out with a modified version of the program ORFLS of Busing, Martin \& Levy (1962). The function minimized was $\sum w\left(\left|F_{0}\right|-k\left|F_{c}\right|\right)^{2}$, where the summation extends over

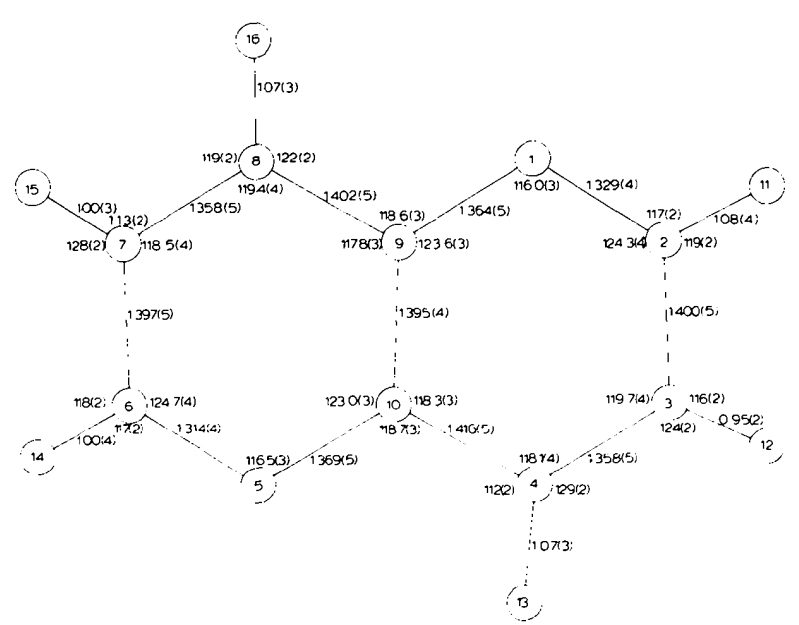

Fig. 1. Bond lengths $(\AA)$ and angles $\left(^{\circ}\right)$ of 1,5-diazanaphthalene. The estimated standard deviations are given in brackets and refer to the last digits.

Table 2. Atomic positional parameters $\left(\times 10^{4} ;\right.$ for $\left.\mathrm{H} \times 10^{3}\right)$

\begin{tabular}{lrcc}
\multicolumn{4}{c}{ l,5-Diazanaphthalene } \\
& $x$ & $y$ & $z$ \\
$\mathrm{~N}(1)$ & $9908(6)$ & $3236(6)$ & $6002(2)$ \\
$\mathrm{C}(2)$ & $10434(7)$ & $3365(9)$ & $5477(2)$ \\
$\mathrm{C}(3)$ & $9253(7)$ & $3498(8)$ & $5025(2)$ \\
$\mathrm{C}(4)$ & $7442(6)$ & $3452(7)$ & $5112(2)$ \\
$\mathrm{N}(5)$ & $4995(5)$ & $3287(6)$ & $5760(2)$ \\
$\mathrm{C}(6)$ & $4480(7)$ & $3169(9)$ & $6281(2)$ \\
$\mathrm{C}(7)$ & $5650(7)$ & $3069(8)$ & $6734(2)$ \\
$\mathrm{C}(8)$ & $7456(7)$ & $3106(8)$ & $6638(2)$ \\
$\mathrm{C}(9)$ & $8090(6)$ & $3202(6)$ & $6090(2)$ \\
$\mathrm{C}(10)$ & $6816(6)$ & $3317(6)$ & $5665(2)$ \\
$\mathrm{H}(11)$ & $1187(6)$ & $332(6)$ & $540(2)$ \\
$\mathrm{H}(12)$ & $980(5)$ & $356(5)$ & $467(1)$ \\
$\mathrm{H}(13)$ & $636(5)$ & $362(5)$ & $482(1)$ \\
$\mathrm{H}(14)$ & $315(7)$ & $310(7)$ & $635(2)$ \\
$\mathrm{H}(15)$ & $533(6)$ & $285(7)$ & $713(2)$ \\
$\mathrm{H}(16)$ & $836(5)$ & $316(5)$ & $699(1)$
\end{tabular}

$\begin{array}{ccc}\text { 2,6-Diazanaphthalene* } & \\ x & y & z \\ 2395(2) & 7617(2) & 36(1) \\ 3820(2) & 7445(1) & 1000(1) \\ 3220(2) & 5545(2) & 1659(1) \\ 1256(2) & 3848(2) & 1381(1) \\ 291(2) & 5967(1) & -348(1) \\ 288(2) & 896(2) & -45(1) \\ 437(2) & 546(2) & 237(1) \\ 93(2) & 257(2) & 187(1)\end{array}$

$*$ The coordinates
$y \rightarrow 1-y, z \rightarrow-z$. 
all non-equivalent reflexions. $\left|F_{o}\right|$ and $F_{c}$ are the observed and calculated structure factors, $k$ is the scale factor. The weight, $w$, for each reflexion was taken to be $w=\sigma^{-2}$, where $\sigma$ was the estimated standard deviation in $\left|F_{o}\right| . \sigma$ was calculated from the variance of the intensity, $S^{2}(I)$, using an expression given by Rees (1976). The atomic scattering factors used for $\mathrm{C}$ and $\mathrm{N}$ were as listed in International Tables for $X$-ray Crystallography (1974). The scattering factor for bonded $\mathbf{H}$ was taken from Stewart, Davidson \& Simpson (1965). After some cycles of refinement with non- $\mathrm{H}$ parameters only, all $\mathrm{H}$ atoms were located by means of difference Fourier maps, calculated with the program SPFT (van de Waal, 1975), through the molecular planes.

The parameters varied in the last cycle of refinement were: positional parameters of all atoms, anisotropic thermal parameters of the non- $\mathrm{H}$ atoms, isotropic thermal parameters of the $\mathrm{H}$ atoms, isotropic extinction correction (Larson, 1969) and scale factor.

The weighted $R$ values were: 0.041 for 1,5-diazanaphthalene, and 0.042 for 2,6-diazanaphthalene. The numbers of reflexions used in the refinements were respectively 761 and 1447 of which 501 and 1029 had intensities larger than twice their estimated standard deviations.*

Discussion. The atomic positional parameters as obtained from the final refinement are given in Table 2. Bond lengths and angles and their e.s.d.'s have been calculated with the program ORFFE (Busing, Martin

* Lists of structure factors and anisotropic thermal parameters have been deposited with the British Library Lending Division as Supplementary Publication No. SUP 33640 (16 pp.). Copies may be obtained through The Executive Secretary, International Union of Crystallography, 5 Abbey Square, Chester $\mathrm{CH} 12 \mathrm{HU}$, England.

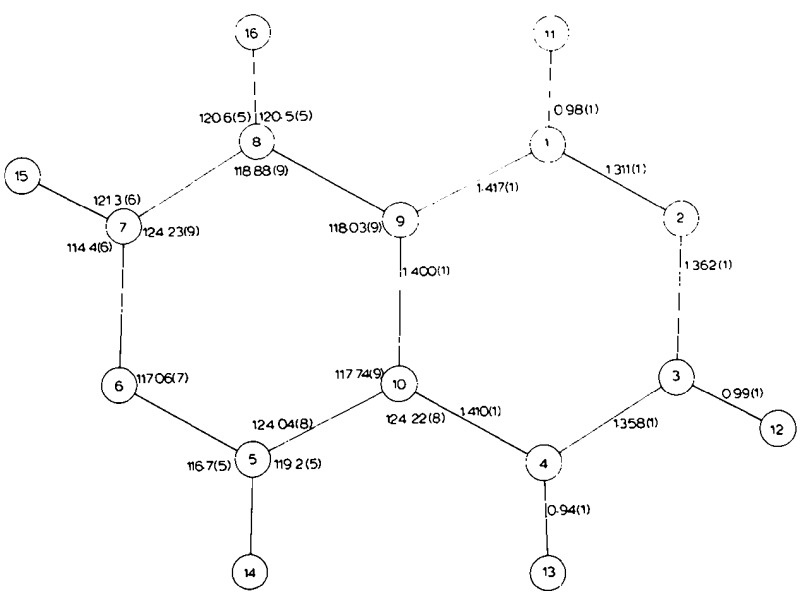

Fig. 2. Bond lengths $(\AA)$ and angles $\left(^{\circ}\right)$ of 2,6-diazanaphthalene. The molecule is situated at a crystallographic centre of symmetry. The estimated standard deviations are given in brackets and refer to the last digits.
\& Levy, 1964). Results are shown in Figs. 1 and 2. The present molecular structural data are in complete agreement with those given by Brufani et al. (1966) obtained from an analysis of the crystal structures of the dihydrates of 1,5- and 2,6-diazanaphthalene. However, the present data also include the positional parameters of the $\mathrm{H}$ atoms and the atomic thermal parameters.

Recently, Lee \& Gilson (1976) reported the proton NMR spectra of the title compounds, partially oriented in the nematic phase of a liquid-crystalline solvent. From the direct dipolar couplings, the ratios of the interprotonic distances in these molecules were obtained.

In their attempt to convert these data into proton geometries, these authors used the ring-atom coordinates as determined by Brufani et al. (1966) and made

Table 3. Atomic deviations ( $\AA$ ) from the best planes through the non- $\mathrm{H}$ atoms

1,5-Diazanaphthalene

Equation of plane $(x, y, z$ are fractional coordinates): $-0.00332 x+2 \cdot 14465 y+0.51228 z=1$

$\begin{array}{lrlrlr}\mathrm{N}(1) & 0.006(4)^{*} & \mathrm{C}(6) & 0.000(6) & \mathrm{H}(11) & 0.05(4) \\ \mathrm{C}(2) & 0.004(6) & \mathrm{C}(7) & -0.005(5) & \mathrm{H}(12) & 0.00(3) \\ \mathrm{C}(3) & -0.016(5) & \mathrm{C}(8) & -0.013(5) & \mathrm{H}(13) & -0.08(4) \\ \mathrm{C}(4) & 0.001(5) & \mathrm{C}(9) & 0.014(4) & \mathrm{H}(14) & 0.04(5) \\ \mathrm{N}(5) & 0.006(4) & \mathrm{C}(10) & 0.003(4) & \mathrm{H}(15) & 0.09(5) \\ & & & & \mathrm{H}(16) & -0.11(4)\end{array}$

2,6-Diazanaphthalene

Equation of plane ( $x, y, z$ are fractional coordinates): $-2 \cdot 25476 x+2 \cdot 00276 y+3 \cdot 70850 z=1$

$\begin{array}{lrll}\mathrm{C}(1) & 0.002(1) & \mathrm{H}(11) & 0.03(1) \\ \mathrm{N}(2) & -0.001(1) & \mathrm{H}(12) & 0.02(1) \\ \mathrm{C}(3) & 0.000(1) & \mathrm{H}(13) & 0.00(1) \\ \mathrm{C}(4) & 0.000(1) & & \\ \mathrm{C}(9) & -0.001(1) & & \end{array}$

* Absence of a sign indicates a deviation towards the reader, a minus sign a deviation away from the reader (see Figs. 1 and 2).
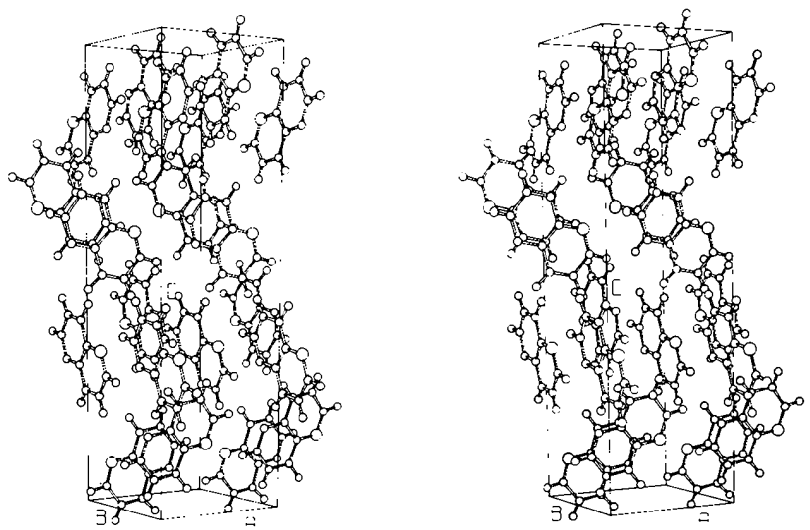

Fig. 3. Stereopair showing the molecular packing of 1,5-diazanaphthalene. The atoms $\mathrm{N}(1)$ are indicated by the larger spheres. 

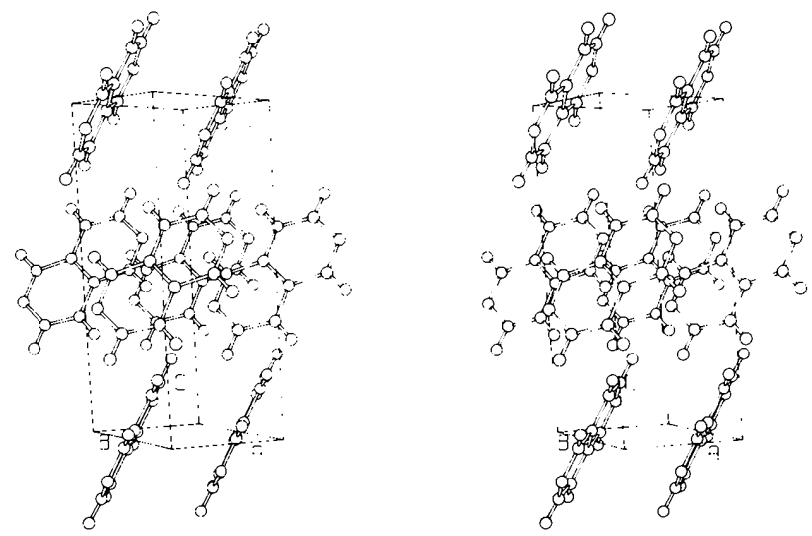

Fig. 4. Stereopair showing the molecular packing of 2,6-diazanaphthalene.

assumptions about the position of one $\mathrm{H}$ atom in each diazanaphthalene.

In a previous contribution, we compared NMR and $\mathrm{X}$-ray structural results for 2,7-diazanaphthalene (Huiszoon, van Hummel \& van den Ham, 1977). Agreement between the results of both experimental methods was obtained when the $\mathrm{X}$-ray $\mathrm{C}-\mathrm{H}$ bond lengths were corrected. The mean value of this correction turned out to be 0.09 (2) A.

Application of this correction to the X-ray $\mathrm{C}-\mathrm{H}$ bond lengths of the title compounds resulted in interprotonic-distance ratios that are, within the limits of accuracy, the same as those obtained by the NMR experiment. The proton geometries obtained in this way differ from those proposed by Lee \& Gilson (1976). This is due to the uncertainties in the assumptions that they had to make concerning the positions of one proton in each compound.

The equations of the least-squares planes through the non- $\mathrm{H}$ atoms and the atomic deviations from these planes have been listed in Table 3. For 1,5-diazanaphthalene there are only small deviations from the plane whereas 2,6-diazanaphthalene can be considered as a planar molecule.

Figs. 3 and 4 are ORTEP (Johnson, 1965) stereopairs showing the molecular packing. The 1,5-diaza- naphthalene molecules are approximately parallel to either the $a$ - or $b$-crystallographic axis. The dihedral angles between the molecular planes of the eight molecules in the unit cell are either close to zero or close to $90^{\circ}$. The following angles occur: 8.4 and $0.2^{\circ}$ (for 'parallel' pairs), and $89.5,89.7$ and $89.9^{\circ}$ (for 'perpendicular' pairs).

The dihedral angle between the molecular planes of the two molecules in the unit cell of 2,6-diazanaphthalene is $68.2^{\circ}$. No unusual intermolecular contacts are present in either structure.

\section{References}

Albert, A. (1960). J. Chem. Soc. pp. 1790-1793.

Brufani, M., Fedeli, W., Giacomello, G., Riccieri, F. M. \& Vaciago, A. (1966). Atti Accad. Naz. Lincei Cl. Sci. Fis. Mat. Nat. Rend. 40, 187-193.

Busing, W. R., Martin, K. O. \& Levy, H. A. (1962). ORFLS. Report ORNL-TM-305. Oak Ridge National Laboratory, Tennessee.

Busing, W. R., Martin, K. O. \& Levy, H. A. (1964). ORFFE. Report ORNL-TM-306. Oak Ridge National Laboratory, Tennessee.

DANIELI, R. \& RiCCI, A. (1973). Synthesis, pp. 46-47.

Germain, G., Main, P. \& Woolfson, M. M. (1971). Acta Cryst. A27, 368-376.

Huiszoon, C., van Hummel, G. J. \& van den HaM, D. M. W. (1977). Acta Cryst. B33, 1867-1870.

International Tables for X-ray Crystallography (1974). Vol. IV. Birmingham: Kynoch Press.

JoHnson, C. K. (1965). ORTEP. Report ORNL-3794. Oak Ridge National Laboratory, Tennessee.

LARSON, A. C. (1969). Crystallographic Computing, edited by F. R. AHmed, pp. 291-294. Copenhagen: Munksgaard.

LeE, Y. P. \& Gilson, D. F. R. (1976). Can. J. Chem. 54, 2783-2787.

McCandlish, L. E., Stout, G. H. \& Andrews, L. C. (1975). Acta Cryst. A31, 245-249.

ReES, B. (1976). Acta Cryst. A 32, 483-488.

Stewart, R. F., Davidson, E. R. \& Simpson, W. T. (1965). J. Chem. Phys. 42, 3175-3187.

WAAL, B. W. VAN DE (1975). SPFT. Slant Plane Fourier Transform Program. Progress Report No. 14. Chemical Physics Laboratory, Twente Univ. of Technology, Enschede, The Netherlands. 